\title{
Implementation of E-Learning Functions With the Use of Information Systems Architecture
}

\author{
Mohammed Khaleel Hussein, Scholarships and Cultural Relations Directorate, Ministry of Higher Education and Scientific \\ Research, Iraq \\ Raffat Izzat Saheel, Directorate General of Education in Diyala, Iraq \\ Ali Jumaah Ali, Ministry of Higher Education and Scientific Research, Iraq
}

\begin{abstract}
E-learning utilizing information systems framework has been booming in information systems. This paper covers the systematic performance evaluation results process, and understanding how e-learning utilizing information system implementation was undertaken for education in the context of universities. The aim of this paper is to analyse the framework of improving e-learning utilizing information system adoption utilizing information system, implementation, and development in higher education. Although e-learning utilizing information systems have been widely used at various education sectors, several fixed outcomes have been calculated. Recent e-learning utilizing information systems structure was implemented utilizing current method and managed for the drawbacks of recent academic technique. There are many things that are not flexible and effective for supporting the real era of this world referring to teaching and learning.
\end{abstract}

\section{KEYWORDS}

E-Learning, Education, Electronic Learning, Information System, Management Information System

\section{INTRODUCTION}

Information is a fundamental asset delivered through information systems and is a key to the administration for dynamic under any association. Information framework can give the savviest asset to the association on the off chance that it is appropriately evolved, oversaw, and utilized (Carina, Pedro, \& Vanesa, 2015). Information framework is characterized as set of individuals, methods, and assets that gathers, changes, and scatters information under an association (Andy, 2004). Information framework likewise alludes to a framework that can incorporate a few coordinated information advances just as hierarchical use and upkeep rehearses that all under all contain a socio specialized marvel (Santhosh, Nazaraf, \& Leonid, 2016). Under this manner, an information framework along regards to this exploration incorporates the innovation, the individuals, procedures and information. To build up a structure for EMIS just as e-learning combination, there is have to know the nuts and bolts about information framework and information framework advancement. Plainly, Information System Development (ISD) is something other than a normal portrayal of the real world. It makes arrangement for speaking to reality past the quantifiable, the visible and the universe of reason. Different perspectives on ISD are quickly talked about. 
As indicated through the practical methodology (likewise called the conventional methodology), ISD is an arranged and normal action did under a deliberate, composed and exact way (Sriram, 2011). The improvement is generally depicted through stages under the advancement life cycle and has a solid innovation centre. Under spite of the fact that a few researchers (Selah \& Sriram, 2011) have agree such an approach and affirm, that the customary origination manages an information framework (IS) as though it existed under seclusion from its human and hierarchical parts and impacts. It likewise set extreme accentuation on the mechanical and bookkeeping/money related perspectives to the detriment of the authoritative and social angles. Other scholars (Rivera, 2016) have attempted to investigate elective methodologies trying to suit social and social factors other than the mechanical under information systems improvement.

Different researchers (CAE, 2018; Khaleel, El-Bakry, \& Saleh, 2014) have saw information framework from direct plan approach and allude to information framework improvement life cycle (ISDLC) as organized techniques that rose during the 1980's and at first utilized under a straight model of the advancement procedure. Clear stages are related to clear sources of info and yields from each stage. The thought was unequivocally supported under information framework improvement yet researchers have concurred that ISDLC is normally treated as an inflexible arrangement of exercises; accordingly they propose an adaptable methodology that is presently the foundation under the administration information systems (MIS) writing and a sign of each advancement exertion. This suggests no MIS action ought to be done without forcing exacting ISDLC methodology, practices and techniques on framework designers (Ahmad \& Mehedi, 2012).

Instruction Management Information System (EMIS) is a coordinated information and information framework that empower educated choices to be made under instructive condition. It gives important information and information through bringing a domain up under which the interest for this information infers its utilization (Agarwal \& Pandey, 2013). UNESCO has built up a structure that is named Instruction Management Information System and definition of Education for everyone: 2002 to 2015 action plan. System attempts to give hypothetical ideas and significant highlights associated along EMIS. The system was readied dependent on the auxiliary school level of instruction. It doesn't give any models that will control the execution of the structure (Abubakar \& Bashir, 2017). Another inquire about was directed so as to reinforce the instruction the board information framework under Tanzania. The examination was led through a Masters understudy under University of Massachusetts Amherst. The exploration calls attention to essential things government can do so as to upgrade existing EMIS under Tanzania so as to have greatest efficiency that will help approach producers under dynamic about instructive arrangements. An exploration directed on Management Information System for Education has looked at the presence of EMIS under both Nigeria and Zambia. The examination talked about additional on the applied parts of information framework lastly calls attention to certain moves identified along existing EMIS under the two nations (Sinan, 2003).

Under any case, there are existing advances and IT arrangements on EMIS all inclusive. For example, UNESCO division of arranging and improvement of training systems have structured nonexclusive programming called Open EMIS. The product was intended to establish an essential, adjustable and reasonable EMIS device for nations along powerless measurable database to have the option to adjust it to the requirements of explicit national settings (Tutorials point, 2018). Different EMIS applications incorporate Federal which is multipurpose school the executives programming that is utilized through a huge number of instructive foundations worldwide for all regulatory, the board, and learning related exercises. Sid mach Technologies is a Nigeria based IT arrangement firm that give EMIS administrations to schools. The firm give e-enlistment arrangements, biometrics arrangements, and start to finish assessment preparing framework.

E-Learning can be seen as learning through electronic methods. It includes obtaining of information and aptitudes utilizing electronic advancements, for example, PC and web (Young, 2013). ELearning empowers you to adapt anyplace and whenever independent of topographical locations. Before the advancement of web, separation courses were offered to understudies on specific aptitudes 
or subjects. Under 1840s, Isaac Pitman for the most part shows his understudies shorthand through correspondence. Under 1954, a Harvard college teacher created an instructing machine that permitted schools to oversee directions to understudies. Under 1960s, the primary PC based preparing (CBT) system defined as PLATO (Automatic Teaching process technique) has been acquainted along the world. PLATO was initially produced for understudies of some College whatever later wound up has been used through different schools inside that region. Under 1970s, e-learning turned out to be all the more fascinating and intelligent as Britain Open University was intrigued to exploit e-learning. Their instructive framework was absolutely on learning at separation. Course materials are typically conveyed to understudies through post and correspondence along mentors or educators are done through mail (Despa, 2014).

Notwithstanding, along the presentation of web, the college conveyed courses materials, instructive encounters just as correspondences to understudies through messages. Increasingly innovative headways were made under 20thand 21 stcenturies to enhance e-learning. These make schools to convey courses on the web and training is generally accessible and available to individuals paying little heed to their geological and time limitations. Business associations likewise received e-learning stages to teach and train their workers. This has given labourers the chances to enhance their mechanical information and abilities towards accomplishing authoritative targets.

E-learning has two (2) classifications that empower understudies to gain from the stage. The strategies for acquiring information from e-learning stage rely upon the student's decision on the class to be utilized. Every one of these classifications has its own advantages and downsides. The two classes are Synchronous and Asynchronous e-learning.

Synchronous-learning is a teacher driven stage that gives ongoing instructing or learning process right away (on the web) to understudies. Both the students and teachers and coaches must be available during the exercise time frame. The classification utilizes continuous apparatus or media, for example, video conferencing and texting or visit. This makes it workable for instructors and understudies to impart and impart information or thoughts to prompt reaction. The significant advantage of synchronous e-learning is the nonattendance of confinement from students which makes them progressively social. Be that as it may, this stage needs adaptability of time (Shaqiri, 2014).

Asynchronous-learning is a self-put learning process that should be possible even disconnected along or without the nearness of the educator or understudies. Coursework and other learning interchanges are conveyed through the web and email. Understudies can experience the web and download course materials just as transfers any pending errand. This stage has advantages of adaptability of time and plans and furthermore enhances level of psychological thinking about the understudies. The main weakness of this stage is that understudies feel like they are separated dealing along their own (Harles, 2015).Several considers have been led on the zone of e-learning framework over the globe. Under inquire about led through researchers on a model for surveying the effect of e-learning systems on the representatives' fulfilment, the examination investigates the methods for improving workers' fulfilment through e-learning. It likewise distinguished different sort of preparing or instructing exercises that are powerful to build representative's learning fulfilment (Assan \& Saxena, 2014). A few creators directed research that investigates the contrasts between e-learning, internet learning and separation learning conditions among individuals. The after-effects of the examination uncovered the presence of contrasts and impression of clients or individuals on e-learning, web based learning and separation learning conditions (Hussein \& Mohammed, 2018). A few specialists led explore towards a model of e-learning under Nigerian higher establishments. The paper was attempting to clarify the product building approaches. It doesn't give any model to e-learning framework (Mohammed, 2015). This research organized as under Section 2 described related literature review, Under section 3 described methodology of related research, Section 4 depict about results analysis of work and Section 5 described conclusion and future work 


\section{LITERATURE REVIEW}

Carina, Pedro, and Vanesa (2015) present a proposition dependent on the use of nimble SDM into instructive programming along accentuation on the SCRUM, Lean UX. The investigation embraced a few qualities of deft strategy which permitted them to utilize models that concentrated on the clients just as get criticism from the clients. Be that as it may, the examination focused on the use of the product on clients along a custom curriculum needs (SEN).

Andy (2004) present an e-learning stage explicitly for encouraging software engineering courses Under Hong Kong colleges. Paper gives advantages of ATLM just as the design procedure of the philosophy. The stage is utilized for sharing blogging, remarking, and texting.

Santhosh, Nazaraf, and Leonid (2016) explore centres around a cosmology driven methodology for a semantic online instructive systems. An enhanced and logical agile technique got through developed programming building procedure model has been utilized for cosmology improvement. The research clarifies sophistically and building parts of recently determined philosophy. Stages and system of philosophy which is used for build up an instructive cosmology.

Sriram (2011) shows normal necessities for instructive programming advancement. It thought about the two instructors and students viewpoints. The exploration gives a lot of consideration on the examination period of programming improvement life cycle (SDLC). The examination attempted to address the inconsistencies that exist under SDLC investigation stage between instructive necessities and programming elements to upgrade the instructive programming use under instructive exercises. The examination gathered some essential information from the two students and teachers for distinguishing proof of client prerequisites reason. Other information was for the most part gathered from auxiliary sources related instructive programming, client prerequisites and SDLC.

Selah and Sriram (2011) portrayed instructive programming has streamlined such a large number of procedures in training area. This instructive programming ought to follow certain formative systems so as to spur the end clients to use the product possibilities. In an exploration titled "instructive programming advancement life cycle" recommends proposition to follow in instructive programming improvement life cycle (ESDLC). The possibility of the examination is to recognize different issues under actualizing instructive programming under educating and learning process. The exploration likewise utilizes both essential and auxiliary information.

Rivera (2016) recognized chances and difficulties of programming improvement approaches utilized under higher instructive organizations particularly under United States. The product improvement groups in advanced education generally need figuring out how to acclimate along these difficulties so as to viably and effectively build up their product ventures. This will help under tending to the fast changes happening under both training part and innovation industry.

CAE (2018) portrayed E-learning stage obliges learning the board framework (LMS) which gives such huge numbers of focal points that help up close and personal and web based learning strategies. The LMS has got generally speaking accomplishment the board of authoritative preparing forms that encourage and enhance the conventional instruction or learning techniques. LMS can spare expense for associations as far as time and cash through easy administration of enormous volume of information and information under an easy to understand way through methods for web-based environment. A great LMS can viably oversee client enlistments, for example, login, information exchange, understudies, courses, online substance, coaches, administrators, schedules, hours, gatherings, get to, warnings, correspondence/messages, testaments and reports.

Ahmad and Mehedi (2012) portrayed E-learning can be viewed as the utilization ICT instruments under upgrading learning process. It is the mix of learning and the Internet innovations that give learning under simpler way to individuals just as fulfil their inclinations. E-learning gives quality training to remote and provincial zones. It estranges the issue of physical foundations generally experience through the organizations of learning. An examination led through scientists titled "An E-learning System for Quality Education" shows a framework model for improving instruction level 
and enthusiasm of understudies under training framework. The investigation gives accentuation on scholarly opportunity, premium and high calibre under training.

Agarwal and Pandey (2013) investigated the period when the idea of e-learning was presented, plot the essential standards of e-learning just as correlation of e-learning along conventional training framework. The examination has displayed the predominance of e-learning over the customary learning regarding efficient for preparing, cost and better viability. The examination shows that e-learning has advanced understudy learning and gets improvement the procedure of instructive preparing which showed up under a few viewpoints, for example, utilization of different learning designs which bargains with combining both on the web and study hall learning strategies, development of study assets which manages educational program assets storage facility and learning assets storage facility (Khalaf \& Abdulsahib, 2019), and improvement of specialized emotionally supportive network which manages the ICT foundation (Khalaf, Abdulsahib, \& Sadik, 2018), the stage itself, the executives framework and upkeep or bolster programming and devices (Khalaf, Abdulsahib, Kasmaei, Ogudo, 2020).

Abubakar and Bashir (2017) depicted The MIS helps under bringing innovative improvement that make great administration conceivable through improving areas like open organization, instruction, wellbeing, farming, and condition. It gives space for gathering and putting away information that can be recovered and utilized for dynamic at whatever point the emerge.

Sinan (2003) portrayed the associations have just divided assortment of procedures for delivering and looking after programming. Three strategies were among the different developing systems and techniques that concentrated on delivering and maintaining programming all the more successfully as at that period, and every strategy has its own displaying language. These strategies incorporate Grady's Booch '93 strategy (from Booch '91) which stresses the plan and development of programming systems, Modeling method of James Rumbaugh's which underlines examination of programming methods, and under conclusion Object Oriented Software Engineering technique of Ivar Jacobson's which underscores corporate designing and necessities investigation.

\section{RESEARCH METHODOLOGY}

Research strategy is normally a sorted out method for illuminating or disentangling research problems (i.e. a specialty of considering how research is done under a sorted out way). Different advances received through the scientists are been inspected during the direct of research while contemplating issues related to the rationale related along the issues. The scientists don't just require realizing the abilities to build up some files or tests figure the mean, mode or middle, standard deviation and so on. They similarly require having aptitudes on how these strategies or strategies are significant or pertinent and which ones are not significant or important, and what are the signs of picking such methods. More or less, investigate approach comprises of strategies and systems and the rationale behind utilizing them under the structure of inquires about or contemplates.

\subsection{Research Design}

The investigation is intended to consolidate study and displaying approach. The overview makes methods for gathering crude information from the partners and interviewers under instructive foundations. The info and the information were examined and use for picking suitable programming advancement strategy and set up the SDM structure too for the instructive foundation. The plan of the models was accomplished utilizing graphical strategies. The methods delineate the entire techniques under instructive establishments that require the utilization of MIS and E-learning and gives clear signs for planning and executing information framework or e-learning stage under instructive systems.

\subsection{Architecture of Validation}

Approvals are strategy of observing structure has been pertinent either no. For approving system, an example of fifty replies has been chosen from everyone taking part colleges utilizing purposive 
inspecting strategy. Five understudies and five staff individuals were picked from every college to react to the approval survey.

\subsection{Problem Statement}

Improvement of programming are normally done through SDMs. Albeit, some product engineers don't carefully follow or follow the procedure of programming advancement techniques, under this way the improvement or configuration approach may work for little applications or ventures, and when the framework develops, it might experience issues as far as new functionalities. Under any case, existing systems depend on the general programming ventures developments or improvements without managing programming determination or control claim to fame. Instructive framework doesn't have a particular or clear approach for instructive programming. The model is explicitly on methodology for showing understudies' product improvement strategies and utilization of the systems. The British and Colombia service of instructions has additionally made report entitled "framework improvement life cycle (SDLC) techniques - BPP arrangement of bearing". The reason for the record is to push the general SDMs without clear necessities to instructive systems. The archive is making accentuation about business process arranging (BPP) just as spelt out headings and places of the service's ventures. Also, instructive organizations embrace the utilization of MIS and e-learning stages utilizing on the web administrations. Understudies and staff will get to these administrations along their own PDAs or gadgets. This will prompt the age of large information for the organizations. The understudies on occasion will under general go astray their brains from concentrating on the examinations. They might be utilizing the gadgets not under a legitimate way, for example, burning through on important time on informal community.

\subsection{Objectives of the Study}

The fundamental point of the investigation is to assemble a product advancement structure for instructive framework to be received under executing MIS and E-learning under instructive foundations. The examination has the accompanying targets:

1. To build up the SDM model for E-learning the executives along information framework

2. To convey examination and look at the present MIS and e-learning stages utilized under higher instructive establishments under the chose creating nations.

3. To distinguish appropriate programming improvement technique for executing MIS and e-learning under higher instructive foundations.

4. To plan MIS and e-learning models for advanced education framework.

\subsection{Implementation Framework}

This area clarifies how E learning incorporation system has been created and furthermore how it tends to be applied. The segment additionally shows the different hypotheses, models or potentially systems based on that $\mathrm{E}$ learning structure has been manufactured.

\subsubsection{Variables}

That is assembled through both writing and essential information as prior clarified. Table 1 shows the fit builds, thoughts or potentially factors obtained from writing and those recommended through interviewers.

\subsection{2. e-Learning Integration Framework}

Right now, learning joining can be accomplished through three stages for example prior to coordination, during mix and after joining. Prior to coordination, various exercises, for example, Analyze reconciliation exercises, Analyze client qualities, learning elements observation, condition 
of learning observation, adopt learning strategies, comparison of choices, manage entities spending plan, and observe subsidizing data completed. Partners answerable for playing out recorded exercises incorporate the college, the teachers and the understudies.

During the joining stage, various exercises are done. These incorporate execution of eye to eye and e-learning methodologies, after which, the two techniques for example vis-à-vis exercises along e-learning exercises ought to be coordinated. During reconciliation the actualizing colleges ought to guarantee which is accompanying E learning highlights has been available under its E learning stage (s).

Sound learning, learning of video, Communication gatherings, Elements informing, Data administration, News sheets, Maps, relaxation games, partners answerable regards executing that has been college, instructors, understudy, private segment and legislature.

After joining, accompanying exercises ought to be completed to guarantee that incorporated systems work appropriately as indicated through the arrangement under stage 1 . These exercises incorporate assessing coordinated systems, assessing understudies' presentation, assessment of teachers' exhibition, mechanical enhancements, assessment of difficulties, and constant client preparing. The important partners for executing these exercises incorporate the college, the speakers, the understudy, government, and the private area.

\section{RESULTS AND DISCUSSION}

\subsection{Validity and Reliability Results}

According to the interviewers Data has been created for testing validity and reliability of this study in Table 1.

Table 1. Validity and Reliability for e-learning framework

\begin{tabular}{|l|c|c|c|}
\hline \multicolumn{1}{|c|}{ Objects } & Numbers & Reliability & Validity \\
\hline Capacity of E learning framework & 11 & 0.904 & 0.804 \\
\hline Movements of conventional learning Vs. E learning & 9 & 0.847 & 0.798 \\
\hline E learning vs. ISL advantages & 7 & 0.862 & 0.882 \\
\hline E learning collaboration infrastructure & 6 & 0.846 & 0.789 \\
\hline E learning enhancement solution & 6 & 0.823 & 0.704 \\
\hline variables needed for E learning Collaboration & 10 & 0.886 & 0.790 \\
\hline
\end{tabular}

Results in Figure 1 it is shown that index of all objects indicate above 0.7 and Cron Bach Alpha's showing 0.8 which is obtained through interviewers.

\subsection{Interviewers Occupation}

Occupation of interviewer's outputs shown in Table 2.

The outcomes in Figure 2 show that most of interviewers which is Student's and Asociate Lecturer's along freq $=222$ and 24 separately. This was trailed through Teaching asociates and Lecturer's freq $=9$. Senior's Lecturer's, Associate Professor;'s and IT workers has been least spoken to along freq $=4,3$ and 1 separately. No Professors took part under the examination. 


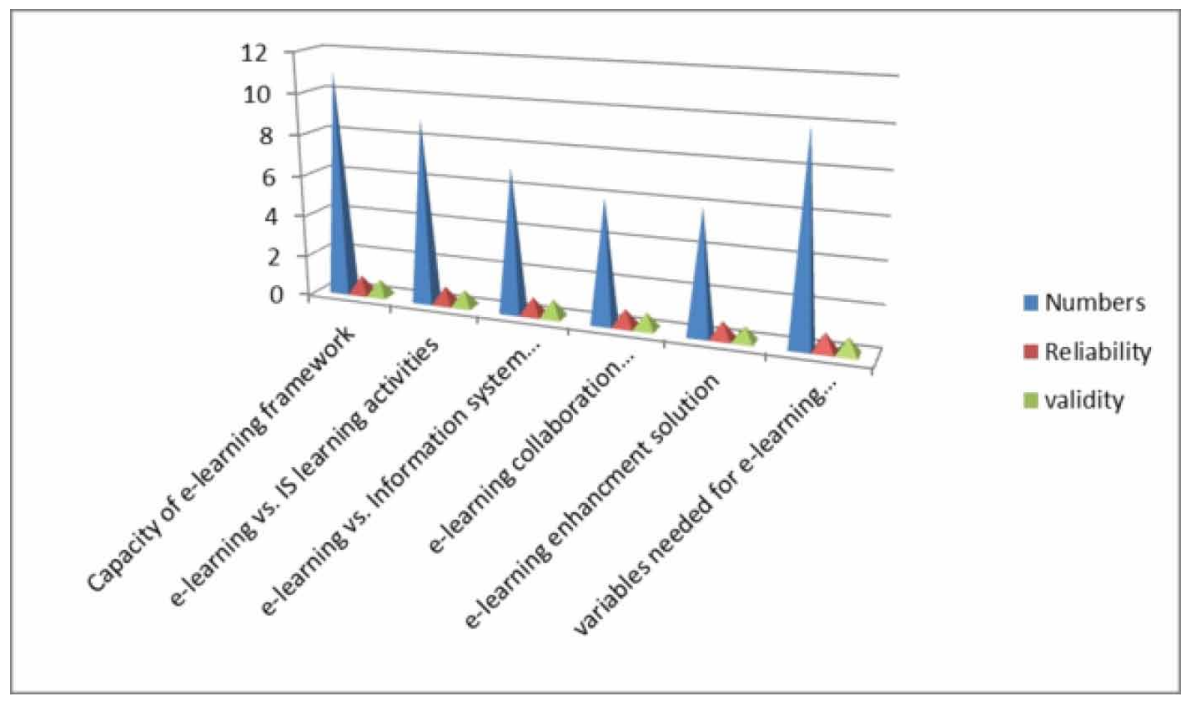

Table 2. Interviewers' occupation e-learning and IS

\begin{tabular}{|c|c|c|c|c|}
\hline Occupation & Frequency & \% & Valid \% & Cumulative \% \\
\hline Teaching's associate & 9 & 4.0 & 4.0 & 4.0 \\
\hline Associate Lecturers & 24 & 9.7 & 9.7 & 12.8 \\
\hline Lecturer's & 9 & 4.0 & 4.0 & 15.8 \\
\hline Senior's Lecturer's & 4 & 2.2 & 2.2 & 16.9 \\
\hline Assistance Professor's & 3 & 0.6 & 0.6 & 18.4 \\
\hline Professor's & 1 & 0.1 & 0.1 & 17.3 \\
\hline IT workers & 1 & 0.9 & 0.9 & 101.0 \\
\hline Student's & 222 & 84.2 & 84.2 & $\mathbf{2 0 3 . 2}$ \\
\hline Total & $\mathbf{2 7 3}$ & $\mathbf{1 0 5 . 7}$ & $\mathbf{1 0 5 . 7}$ & \\
\hline
\end{tabular}

\subsection{Capacities of e-Learning Platform}

Respondent's has been gotten some information regarding capacities of E learning stages. Unmistakable methods which utilized for investigating information depend on Likert scale of 5 points, also mean near 1 suggested solid difference when mean near 5 inferred solid understanding. Table 3 shows discoveries.

Results from essential information under Figure 3 show that interviewers firmly concurred that their e-learning stages bolstered conversation gatherings mean has been 4.43 , release sheets mean has been 4.78 , chart rooms mean has been 4.03 and email mean has been 4.52 capacities. Interviewers were questionable if $\mathrm{E}$ learning stages has been data administration abilities. Respondent's anyway unequivocally differ if $\mathrm{E}$ learning stages has been sound learning mean has been 1.44, learning $\mathrm{f}$ video mean has been 1.78 , texting mean has been 2.48 , games and recreation mean has been 2.48 and connecting along tests mean has been 2.30 capacities. 
Figure 2. Interviewers' designation e-learning and IS

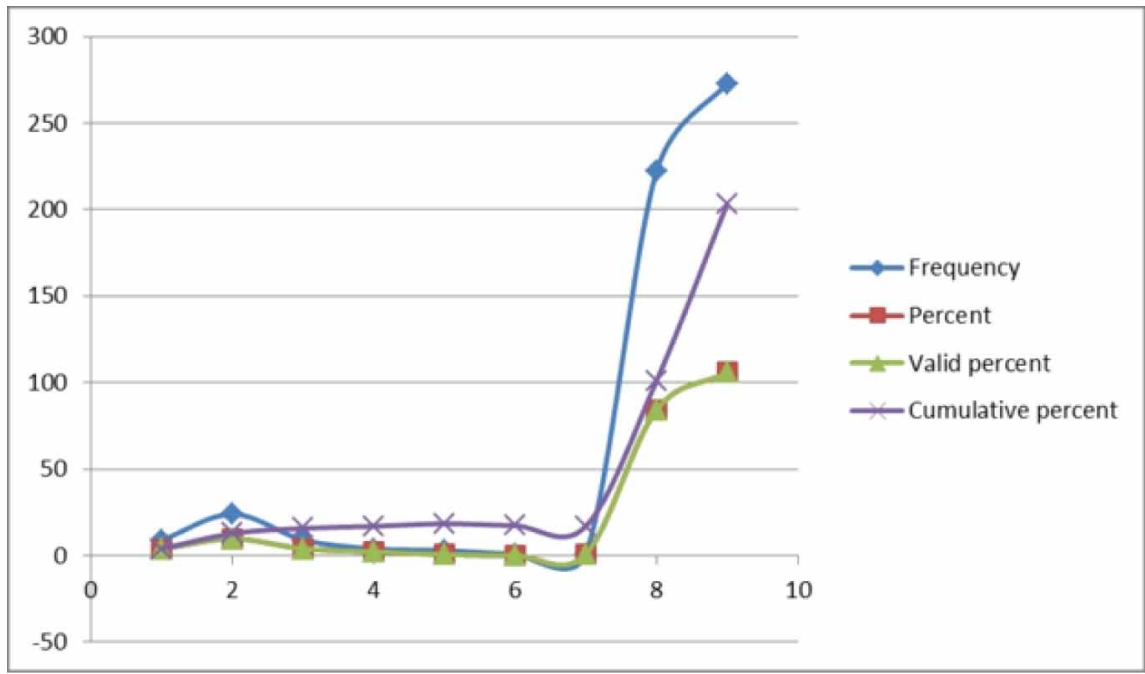

Table 3. Capacities of e-learning platform

\begin{tabular}{|c|c|c|c|c|}
\hline Capacities & Min calc. & Max calc. & Mean calc. & Standard Deviation \\
\hline Learning of audio & 2 & 5 & 1.44 & .21 \\
\hline Learning of video & 1 & 5 & 1.78 & .50 \\
\hline Forums of discussion & 3 & 5 & 4.43 & .00 \\
\hline Messaging & 1 & 5 & 3.48 & .41 \\
\hline Arrangement of contents & 2 & 5 & 4.78 & .06 \\
\hline Boards of news & 1 & 5 & 4.03 & .08 \\
\hline Chartrooms & 1 & 5 & 2.48 & .14 \\
\hline Games of study & 1 & 4 & 2.30 & .79 \\
\hline Daily quiz & 1 & 4 & 4.52 & .30 \\
\hline mailing & 2 & 5 & 5 & \\
\hline
\end{tabular}

\subsection{Needs of e-Learning Integration}

Information was gathered on necessities for e-learning coordination and broke down. The outcomes under Table 4 showing interviewers firmly concurred which necessities for reconciliation regards E learning and another learning strategies has been; utilization of projectors mean has been 4.85 , utilization of E learning for talks and up close and personal for tests and tests mean has been 4.84 , blending course material regards E learning and face to look under configuration stage mean has been 4.87, joining 3D images under up close and personal speakers mean has been 4.56, utilization of recordings for enhancing long separation understudies learning encounters mean has been 4.72 , utilization regards sound tapes for playing addresses under face to face classes for enhancing understudies' learning encounters mean has been 4.69 , utilization of visitor instructors mean has been 
Figure 3. Capacities of e-learning platform

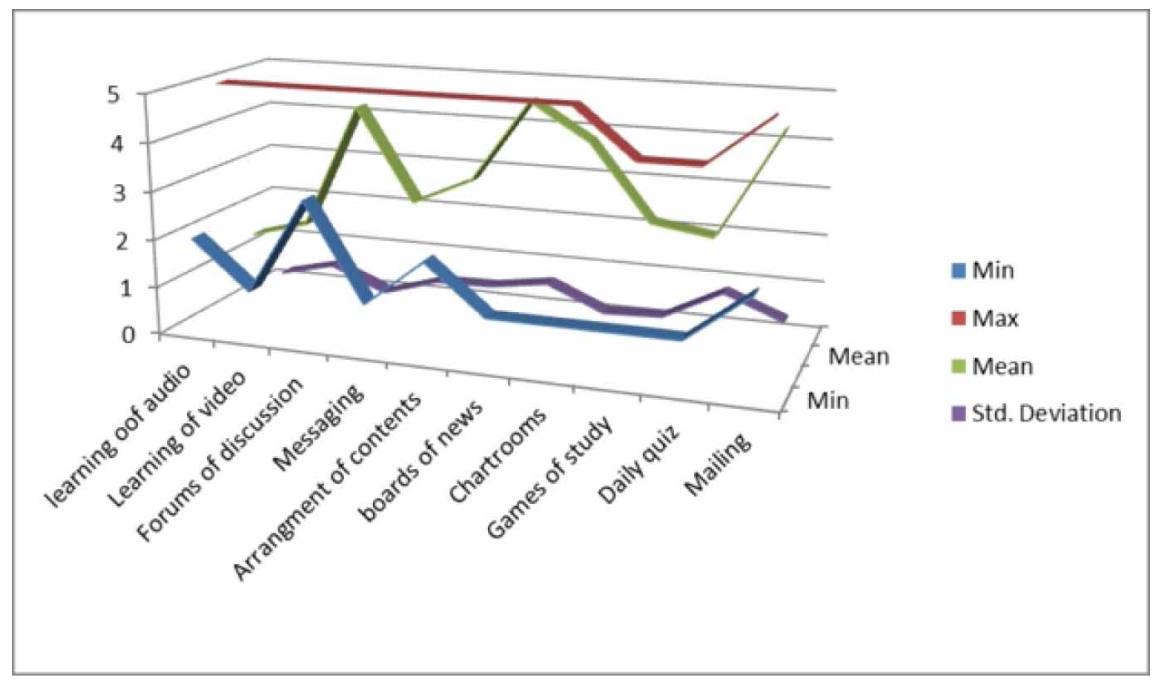

Table 4. Needs of E learning collaboration

\begin{tabular}{|c|c|c|c|c|}
\hline Needs & Min Calc & Max Calc & Mean Calc & $\begin{array}{l}\text { Standard } \\
\text { Deviation }\end{array}$ \\
\hline Projector's utilization & 1 & 5 & 4.85 & .81 \\
\hline $\begin{array}{l}\text { Techniques of E-learning must utilized } \\
\text { lectures and examination must through face } \\
\text { to face technique }\end{array}$ & 3 & 5 & 4.84 & .34 \\
\hline $\begin{array}{l}\text { Course contents must harmonized } \\
\text { framework to permit so it is utilized under } \\
\text { e-learning and face to face technique }\end{array}$ & 1 & 5 & 4.87 & .78 \\
\hline Incorporate $3 \mathrm{D}$ pictures & 2 & 5 & 4.56 & .97 \\
\hline $\begin{array}{l}\text { Videos utilization for enhancing students } \\
\text { learning of distance education }\end{array}$ & 2 & 5 & 4.72 & .92 \\
\hline $\begin{array}{l}\text { Audio utilization under face to face lectures } \\
\text { for enhancing learn quality }\end{array}$ & 1 & 5 & 4.69 & .21 \\
\hline $\begin{array}{l}\text { Guest lecturers must invited for seminar of } \\
\text { student which covered topics online }\end{array}$ & 1 & 5 & 4.89 & .72 \\
\hline $\begin{array}{l}\text { Before starting online lectures books and } \\
\text { reading notes must given to students for } \\
\text { better understanding }\end{array}$ & 1 & 5 & 4.66 & .53 \\
\hline $\begin{array}{l}\text { Students must know utilization of } \\
\text { e-learning techniques before they start } \\
\text { learning }\end{array}$ & 1 & 4 & 4.75 & .85 \\
\hline
\end{tabular}


4.89, utilization of course books and another perusing materials 1st beginning on the web addresses mean has been 4.66 , preparing students on the most proficient method to utilize e-learning methods before starting courses mean has been 4.75 .

\subsection{Stakeholders for e-Learning Integration}

Table 5 shows the successful collaboration of E learning for stake holders, findings analysed according to this.

Results under Figure 5 demonstrate that interviewers firmly concurred that colleges mean has been 5.88, the administration mean has been 5.76, addresses mean has been 5.86, understudies mean has been 5.73 and private division mean has been 5.55 when key partners regards fruitful incorporation of e-learning through HEIs. The necessities regarding mix of E learning and another learning techniques which has been distinguished like utilization of projectors, blending up close and personal and e - learning, orchestrating course objects for E learning and face to face under configuration stage and consolidation of 3D images under eye to eye. What's more, the utilization of recordings, sound tapes, visitor speakers, course books and other understanding materials and preparing were likewise recommended as prerequisites for fruitful coordination of e-learning.

\section{CONCLUSION AND FUTURE WORK}

The focal point of the examination is to structure a SDM system that will incorporate the usage of MIS and E-learning in instructive organizations. In accomplishing that, five (5) objectives were defined. These targets comprise of leading investigation and assessment of the present MIS and e-learning stages utilized in higher instructive foundations in creating nations, distinguishing appropriate programming advancement strategy for executing MIS and e-learning in higher instructive organizations, plan MIS and e-learning models for advanced education framework, structure models incorporating enormous information into the system for improving educating and learning in instructive establishments. Configuration models for coordination of IoT inside the structure for improving instructing and learning in instructive establishments. In future the proposed AIIMES system ought to be executed and embraced through programming designers in creating MIS and E-learning applications in instructive foundations. E-learning stage ought to be utilized at different parts of instructive foundations. 
Figure 4. Needs of e-learning integration

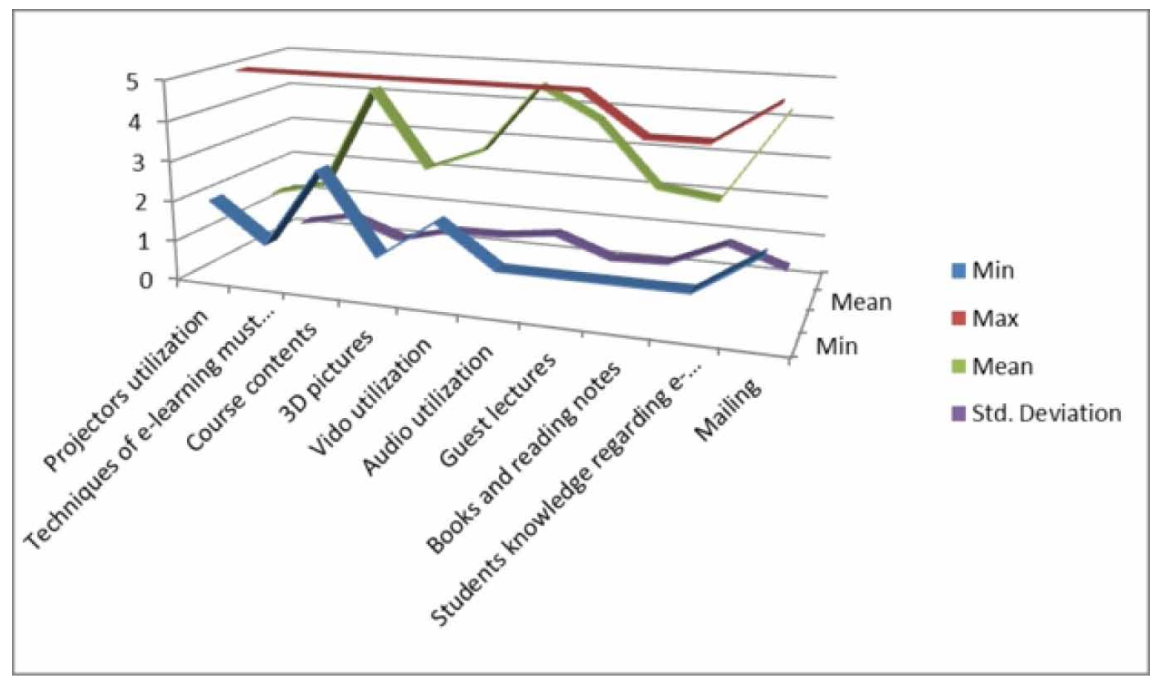

Table 5. Stake holders for E learning collaboration utilizing MIS

\begin{tabular}{|l|l|l|l|l|}
\hline \multicolumn{1}{|c|}{ Stake holder } & \multicolumn{1}{|c|}{ Min calc } & \multicolumn{1}{c|}{ Max calc } & \multicolumn{1}{c|}{$\begin{array}{c}\text { Standard calc } \\
\text { Deviation }\end{array}$} \\
\hline Counts of Universities & 2 & 6 & 5.88 & .23 \\
\hline Counts of Government & 2 & 6 & 5.76 & .43 \\
\hline Counts of Lecturers & 2 & 6 & 5.86 & .24 \\
\hline Counts of Students & 2 & 6 & 5.73 & .25 \\
\hline Counts of Private sector & 2 & 6 & 5.55 & .02 \\
\hline
\end{tabular}

Figure 5. Stakeholders for e-learning integration utilizing MIS

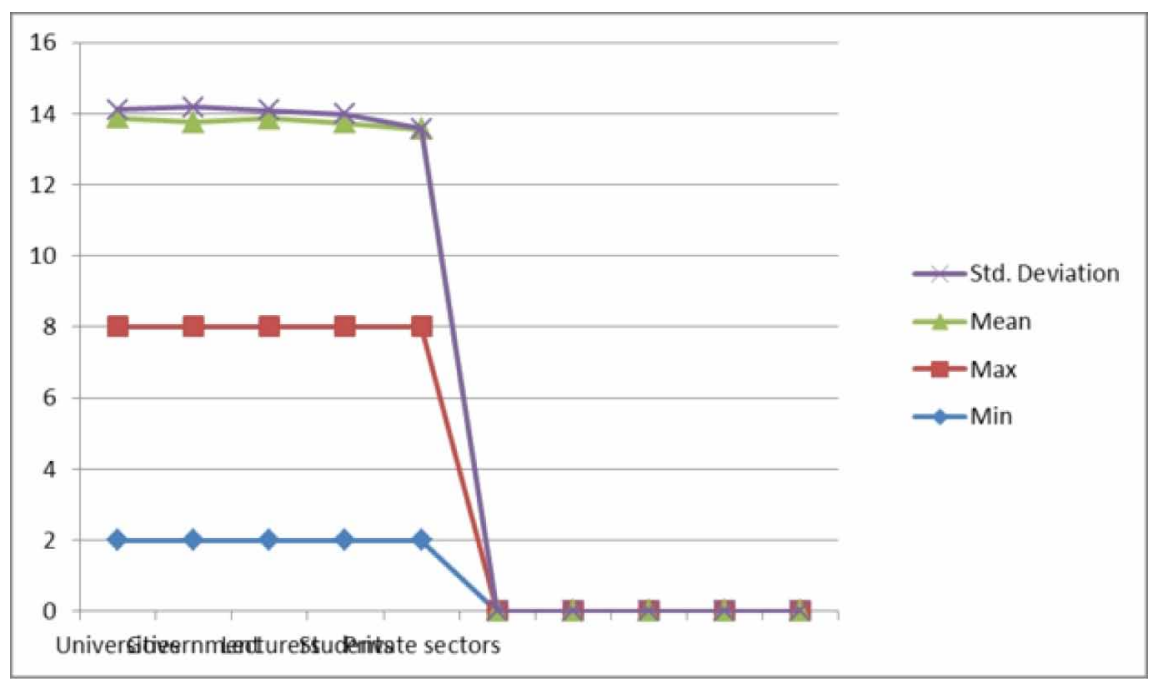




\section{REFERENCES}

Abubakar, M., \& Bashir, M.S. (2017). Centralized Database: A Prerequisite for Security and Sustainable Development in Nigeria. International Journal of Innovative Research in Computer Science and Technology, 5(1), 209-213.

Agarwal, H., \& Pandey, G. N. (2013). Impact of E-learning in Education. International Journal of Scientific Research, 2(12).

Ahmad, T.S., \& Mehedi, M. (2012). An E-learning System for Quality Education. International Journal of Computer Science Issues, 9(4).

Andy, H. W. C. (2004). The Agile Teaching/Learning Methodology and Its e-learning Platform. International Conference on Web-Based Learning (ICWL)-ICWL 2004, 11-18.

Assan, A. and Saxena, J.P. (2014) Management Information System for Education. Journal of Research and Method in Education, 4(1), 36 -44.

CAE. (2018). 9 Advantages of Learning Platforms or LMS. Learning Management System. CAE Innovative Learning Solutions.

Carina, S. G., Pedro, T., \& Vanesa, M. (2015). Agile human cantered methodologies to develop educational software. Dyna, 82(193), 187-194. doi:10.15446/dyna.v82n193.53495

Despa, M. L. (2014). Comparative Study on Software Development Methodologies. Database Systems Journal, $5(3)$.

Harles, C.V. (n.d.). Education Management Information System(EMIS) and the Formulation of Education For All (EFA). Plan of Action 2002-2015 for UNESCO Almaty Cluster Office and Ministry of Education Tajikistan. (Unpublished)

Hussein, M. K., \& Mohammed, M. A. (2018, January). Efficient and accuracy of retrieval files in E-learning system based on click method. In 2018 1st International Scientific Conference of Engineering Sciences-3rd Scientific Conference of Engineering Science (ISCES) (pp. 34-38). IEEE.

Khalaf, O. I., \& Abdulsahib, G. M. (2019). Frequency estimation by the method of minimum mean squared error and P-value distributed in the wireless sensor network. Journal of Information Science and Engineering, 35(5), 1099-1112.

Khalaf, O. I., Abdulsahib, G. M., Kasmaei, H. D., \& Ogudo, K. A. (2020). A new algorithm on application of blockchain technology in live stream video transmissions and telecommunications. International Journal of e-Collaboration, 16(1), 16-32. doi:10.4018/IJeC.2020010102

Khalaf, O. I., Abdulsahib, G. M., \& Sadik, M. (2018). A Modified Algorithm for Improving Lifetime WSN. Journal of Engineering and Applied Sciences (Asian Research Publishing Network), 13, 9277-9282.

Khaleel, M., El-Bakry, H. M., \& Saleh, A. A. (2014). Developing e-learning services based on cache strategy and cloud computing. International Journal of Information Science and Intelligent System, 3(4), 45-52.

Mohammed, A. (2015). Design and Implementation of an Integrated Data and Information System for Managing Educational Resources (Master's Thesis). Dept. of Information Technology, Modibbo Adama University of Technology.

Rivera, A. D. (2016). Towards a software development methodology for projects in higher education institutions. Open Access Theses. 890. Retrieved from https://docs.lib.purdue.edu/open_access_theses/890on

Santhosh, J., Nazaraf, S., \& Leonid, S. (2016). Incremental and Iterative Agile Methodology (IIAM): Hybrid Approach for Ontology Design towards Semantic Web Based Educational Systems Development. International Journal of Knowledge Engineering, 2(1).

Selah, A., \& Sriram, B. (2011). Educational Software Development Life Cycle. Chinese Business Review, 10(1).

Shaqiri, A.B. (2014). Management Information System and Decision-Making. Academic Journal of Interdisciplinary Studies, 3(2). 
Sinan, S. A. (2003). Learning UML. O'Reilly.

Sriram, B. (2011). Educational Software Development -Users Requirement Analysis. International Journal of Computers and Applications, 31(10).

Tutorials Point. (2018). Management Information System. Tutorials Point (I) Pvt. Ltd.

Young, D. (2013). Software Development Methodologies. Academic Press.

Mohammed Khaleel Hussein was born in Baghdad, Iraq on 11 Nov 1977. He has received B.Sc. in information system of computer, Al-Rafidain University Collage, Iraq (2000-2001). M. Sc. degree in Computer Science, Iraqi Commission for Computers \& Informatics/ Informatics Institute for Postgraduate Studies, Iraq 2004-2005. PhD Degree in Information Systems, Faculty of Computers and Information, Mansoura University, Egypt (2016). He joined in June 2007 Ministry of Higher Education and Scientific Research/ Scholarships and Cultural Relations Directorate, Iraq.

Raffat Izzat Saheel was born in Diali, Iraq on 16 Jun 1981. He has received Technical Diploma in Computer systems, Technical Institute of Baaquba (2003). B.Sc. in Education- computer Education Department, Collage of Basic Education Registration, Diyala University, (2008-2009). M.Sc. degree in information systems, Faculty of Computers and information, Mansoura University Egypt (2016). He joined in Feb 2005 Ministry of Education/Teacher.

Ali Jumaah Ali Al Kaabi was born in Baghdad, Iraq on 19 Dec 1977. He was received B.Sc. in information technology of computer, Al-Mansur University college, Iraq (2002-2003). M.Sc. degree in Software Engineering of Computer Science, Lomkokwing University, Malaysia (2013-2015). He joined in January 2007 Ministry of higher education and Scientific research/ Scholarship and cultural relations Directorate, Iraq. Member of Iraqi cultural Attache in Malaysia (2013-2015). He worked in minister office of Ministry of higher education (2015-now) 